\title{
INTEGRAÇÃO NO ENSINO DE ARQUITETURA E URBANISMO: EXPERIÊNCIAS COM ATELLÊS VERTICAIS
}

INTEGRATION INTO TEACHING OF ARCHITECTURE AND URBANISM: EXPERIENCES WITH VERTICAL ATELIERS

\section{BATISTELLO, PAULA}

Mestre, Unochapecó, paula@batistello.com.br

\section{BALZAN, KATIANE LAURA}

Mestre, Unochapecó, katibalzan@gmail.com

\section{PEREIRA, ALICE T. CYBIS}

Doutora,UFSC, acybis@gmail.com

\begin{abstract}
RESUMO
A discussão da interdisciplinaridade nos cursos superiores em Arquitetura e Urbanismo vem sendo ampliada, principalmente nos últimos dez anos. Os projetos pedagógicos e suas matrizes curriculares vem sendo repensados com vistas à formação de um profissional mais autônomo, crítico e reflexivo. Com este intuito, atividades em ateliês verticais e horizontais tem sido objetos de estudo, de formas experimentais ou curriculares. O presente artigo trata da integração de saberes e conteúdos em ambiente de ateliê vertical, experimentado em três edições da Maratona de Projetos do Curso de Arquitetura e Urbanismo da Unochapecó, atividade que tem ocorrido sempre ao início de cada ano letivo e busca estimular a formação do profissional reflexivo. Foram analisadas e discutidas diferentes categorias da integração de saberes, tendo por base a compreensão e percepção do discente participante da atividade, mediante a aplicação de questionário. Os resultados corroboram o referencial teórico adotado e demonstram que em ambientes de criação mais livres, nos quais o docente atua somente como instrutor, sem interferir nas soluções propostas, o acadêmico se percebe efetivamente como protagonista do processo.
\end{abstract}

PALAVRAS-CHAVE: interdisciplinaridade; ensino de arquitetura e urbanismo; ateliê vertical.

\section{ABSTRACT}

The discussion of interdisciplinarity on higher education in Architecture and Urbanism has been expanded, especially in the last ten years. The educational projects and their curricular matrices has been rethought with the aim to forming a more autonomous, critical and reflective practitioner. To this end, activities in vertical and horizontal ateliers have been objects of study, in experimental or curricular forms. This article focuses the the integration of knowledge and content in vertical ateliers environment, experienced in three editions of Architecture Course Project Marathon and Urbanism of Unochapecó, an activity that has always been in the beginning of each school year and seeks to encourage the formation of reflective practitioner. There were analyzed and discussed different categories of integration of knowledge, based on the understanding and perception of students that participate in activity, obtained by questionnaires. The results corroborate the theoretical framework adopted and demonstrate that in freer environments of creation in which the teacher acts only as an instructor, without interfering in the proposed solutions, the academic effectively perceives himself as the protagonist of the process.

KEY-WORDS: interdisciplinarity; education in architecture and urbanism; vertical atelier.

\section{INTRODUÇÃO}

O ensino de Arquitetura e Urbanismo vêm sendo muito discutido atualmente, principalmente no âmbito da integração dos conteúdos. As práticas individualistas de ateliês, a instabilidade de manutenção de corpo docente para que realize práticas de integração e a falta de experiência didático-pedagógica de docentes em início de carreira, aliados ao pouco tempo de estudo teórico, legitimam o quadro crítico do ensino de arquitetura e urbanismo no Brasil.

Aliada ao crescimento da oferta de vagas e de novos cursos em todo o País, a quantidade de abertura de novas escolas de arquitetura e urbanismo no País intensificou-se a partir 1995, mas do ano 2000 
para cá, a quantidade de novas escolas aumentou em 324\%; como pode ser observado na Figura 1, a interdisciplinaridade também vem sendo discutida em novos e antigos Projeto Pedagógicos de Cursos (PPC). Para exemplificar esses dados, é fácil observar nos cadernos da Associação Brasileira de Ensino de Arquitetura - ABEA (1), que a partir 2005 são mais frequentes e em maior número artigos relatando experiências de integração de conteúdos de forma curricular ou em experimentações, assim como artigos disponíveis no Grupo de Pesquisa em Projeto de Arquitetura e Percepção do Ambiente - Projetar (2). O que se encontra anteriormente a estas experiências, ainda são tentativas de integração entre um conteúdo e outro e não entre os vários conhecimentos da arquitetura e urbanismo. Há de se considerar também que a mudança de ferramentas de projetar (instrumentos manuais ou auxiliados pelo computador) assumiu grande parte da discussão nos anos anteriores.

Figura 1 - Crescimento de abertura de escolas de arquitetura e urbanismo no Brasil de 1820 a 2016.

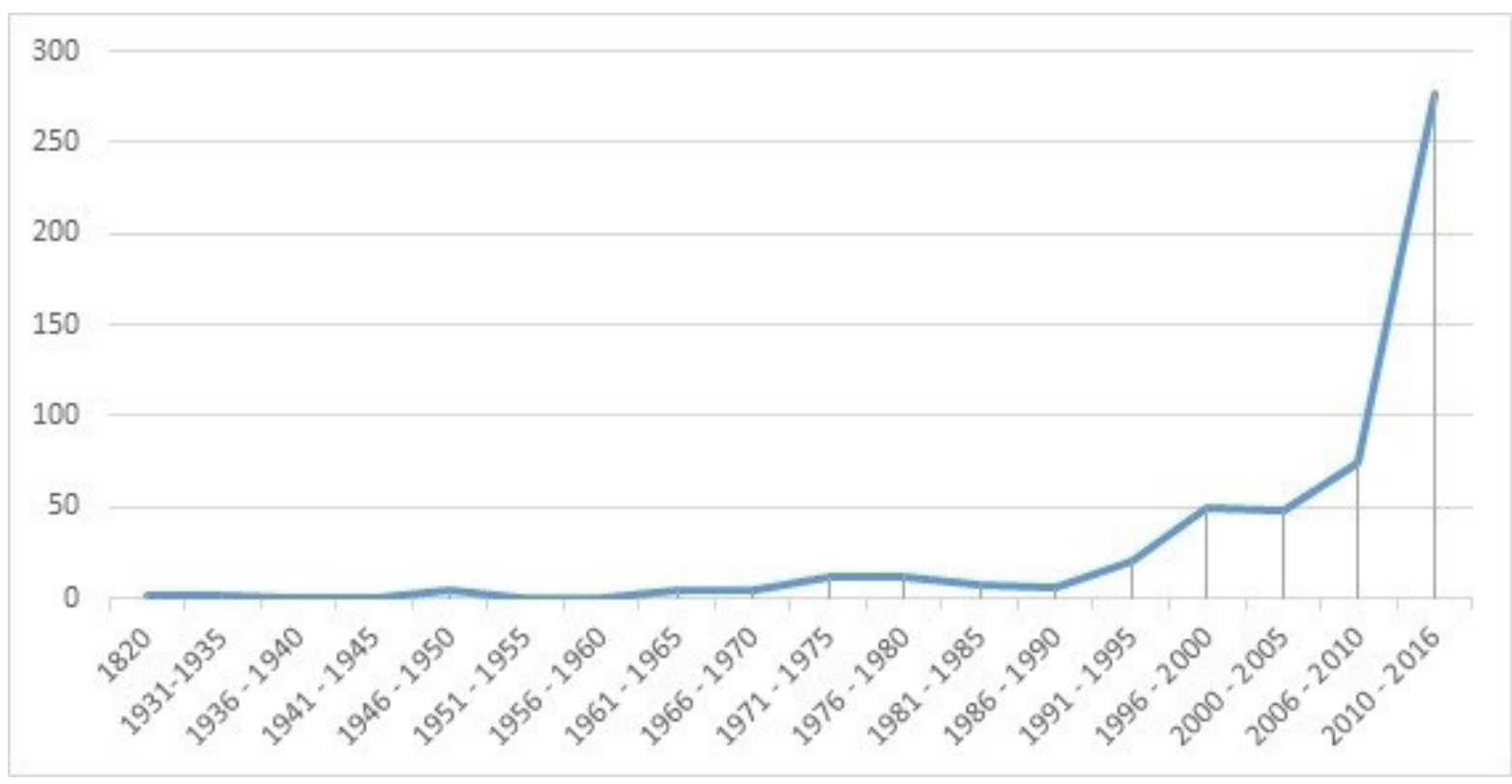

Fonte: Dados da ABEA (http://www.abea.org.br) trabalhados pelas autoras.

Corroborando essa argumentação, Teixeira (2011, p. 7) constata em sua pesquisa que: na docência brasileira vai rareando a presença dos chamados grandes arquitetos, principalmente na graduação; acompanha a abertura dos novos cursos de arquitetura e urbanismo e a demanda por professores - vários deles, sem experiência profissional mais consolidada e nem experiência docente. Não é problema a ausência dos chamados grandes arquitetos, mas, ainda segundo o autor, a falta de experiência profissional e docente faz com que no ensino se repitam as práticas usuais herdadas, enquanto que, por outro lado, pesquisas e referências sobre a produção de arquitetura contemporânea se diversificaram e se ampliaram, afinal e felizmente, ultrapassando com grandes margens o limitado quadro anterior, além do acesso a elas ser imensamente fácil e irrestrito, através da internet.

Assim como já previsto nas Resoluções de 2005 e 2006, a Resolução 02 de 17 de junho de 2010, que institui as Diretrizes Nacionais do curso de graduação de Arquitetura e Urbanismo, em seu artigo $3^{\circ}$ prevê o conteúdo mínimo que deve estar incluso nos currículos plenos dos cursos. Nela, os itens III (Formas de realização de Interdisciplinaridade) e IV (Modos de integração de teoria e prática), expressam a necessidade de integração e interdisciplinaridade, ou seja, as experiências que muitos vêm aplicando em seus cursos com mais frequência a partir de 2005 já devem ser claras e explícitas em cada Projeto Pedagógico de Curso (PPC).

O objeto de análise do artigo é a aplicação de uma proposta pedagógica de integração de conteúdos e tecnologias no processo projetual a partir de uma atividade de Ateliê Vertical: a Maratona de Projetos. 


\section{A INTEGRAÇÃO DE CONTEÚDOS NO PROCESSO PROJETUAL}

De acordo com Lawson (2011, p. 64), os problemas de projeto costumam ser multidimensionais e interativos e raramente o objeto projetado tem alguma parte que sirva a um único propósito. Portanto, ao projetar é necessário frequentemente imaginar uma solução integrada que responda a toda uma aglomeração de exigências.

O bom projeto costuma ser uma resposta integrada a toda uma série de questões. Se houvesse uma característica única que pudesse ser usada para identificar os bons projetistas, seria a capacidade de integrar e combinar. Um bom projeto é quase como um holograma: a imagem inteira está colocada em cada fragmento. Em geral, não é possível dizer qual parte do problema se resolve com qual parte da solução. Elas simplesmente não se correspondem dessa maneira. (LAWSON, 2011, p. 66)

Apesar do citado anteriormente, na formação acadêmica em AU é comum que docentes e discentes se afastem da integração dos conteúdos a partir do aprofundamento do estudo em uma área específica, prática evidenciada pelo isolamento das disciplinas em sala de aula. Mais ainda, nas propostas projetuais desenvolvidas é frequente encontrar soluções que não condizem com todo o conteúdo estudado no decorrer do curso de graduação, em uma sequência de falta de autonomia reflexiva e dependência de solucionar funcionogramas atentados ao cumprimento de programas de necessidades. Nesse contexto, é muito comum os resultados mostrarem suscetibilidade nas soluções técnicas, sejam estruturais, de conforto ambiental, urbanísticas ou ainda históricas e teóricas.

Contudo, as experiências de falta de integração não são exclusividade de cursos que possuem rotatividade no quadro docente, nem dos cursos que possuem um número maior de docentes especialistas. Assim como há a repetição das práticas usuais herdadas nos escritórios da vida profissional autônoma, também há a repetição das práticas herdadas no próprio curso de graduação cursado pelo professor, fazendo repetir os mesmos problemas de antigos PPC's e levando muito tempo para detectar a falta da integração de conteúdos como falha no processo de ensino.

Teixeira (2011, p. 7), afirma que a fragmentação do conhecimento e o distanciamento de prováveis contribuições da área da educação são um "pecado original" de todo o ensino superior. Persistindo nos cursos de arquitetura e urbanismo, mesmo quando todos os docentes estão exclusivamente vinculados a ele, e mesmo quando todos os docentes, em todas as disciplinas, são arquitetos. Esse entendimento é reforçado por um testemunho de Vidigal (2004, p. 125) ao firmar que a questão da integração sempre foi complicada porque você precisa aprender a dialogar e a ceder um pouco. Assim, de um modo geral, quando a integração acontece, é muito proveitosa e produtiva; e quando não acontece, simplesmente não acontece, o que depende muito da empatia entre os professores das disciplinas, uma questão sempre complicada.

Além da empatia entre docentes, parecem ser necessárias atitudes enérgicas de cobrança quanto à efetivação das integrações previstas nos PPC's. Pode-se verificar que a presença de um articulador pedagógico poderia validar as medidas de integração previstas em várias estruturas curriculares (WEIZENMANN; PACHALSKl; DIEMER, 2014; CAVALCANTE; VELOSO, 2013; ESPÍNDOLA; SCHWERTZM, 2013; JÁCOME; VIEIRA, 2013; TEIXEIRA, 2011). Mesmo assim, alguns casos exemplificados em congressos que debatem o ensino de arquitetura e urbanismo no Brasil, mesmo escolas que contam com a presença de uma pessoa organizadora responsável pela integração dos conteúdos (papel do articulador pedagógico), reclamam da falta de adesão docente. Como exemplo desse tipo de situação, o relato de Jácome e Vieira (2013) analisam o curso de uma IES privada no qual há Projeto Interdisciplinar, no entanto, as atividades são desenvolvidas em cada uma das disciplinas, em separado. Segundo os autores, as atividades realizadas em cada disciplina precisam estar relacionadas ao conjunto de atividades do semestre corrente (integração horizontal), bem como com os conhecimentos adquiridos nos semestres anteriores (integração vertical), porém isto nem sempre acontece. Além disso, em algumas disciplinas o Projeto Interdisciplinar acontece totalmente em paralelo às atividades específicas da disciplina, constituindo-se, assim, quase como outro componente curricular independente. Ainda segundo os autores, acredita-se que, para alcance da desejada integração é essencial conscientização dos professores e que eles se engajem em um trabalho participativo. Tratando-se de uma experiência que se desenrola em instituição privada, é preciso destacar que uma participação mais ativa é dificultada por se tratar de um grupo pequeno de professores que dividem seu tempo entre vários cursos, dificultando o encontro para reflexões. 
Foram elencados aqui quatro problemas cruciais para a falta da integração ser tão persistente na prática da integralização dos nossos currículos: (i) a falta de conhecimento docente; (ii) a falta de empatia entre docentes; (iii) a falta de articulador pedagógico; (iv) falta de autonomia reflexiva discente.

Schön (2000) discute muito a prática do profissional reflexivo e alia a ela o ensino prático reflexivo, voltado para ajudar os estudantes a adquirirem os tipos de talento artístico essenciais para a competência em zonas indeterminadas da prática, repensando a epistemologia da prática e pressupostos pedagógicos sobre seus currículos. Baseado neste ensinamento de educar o profissional reflexivo pode apresentar-se uma melhoria nas respostas de tentativas de integração de conteúdos aplicadas nas escolas em geral, pois refletindo sobre seus atos, o próprio acadêmico terá autonomia de aliar os conhecimentos.

É base deste ensinamento a linguagem usada pelo docente, principalmente para não dar a resposta pronta aos problemas encontrados e, no caso de docentes de arquitetura e urbanismo, poder-se-ia não desenhar soluções ao problema levantado pelo acadêmico.

Ao estudante, não se pode ensinar o que ele precisa saber, mas se pode instruir. Ele tem que enxergar, por si próprio e à sua maneira, as relações entre meios e métodos empregados e resultados atingidos. Ninguém mais pode ver por ele, e ele não poderá ver apenas 'falando-se' a ele, mesmo que o falar correto possa guiar seu olhar e ajuda-lo a ver o que ele precisa ver. (DEWEY, 1974 apud SCHÖN, 2000, p. 25)

A partir desse embasamento do profissional reflexivo, implantado e discutido na Unochapecó nos últimos três anos, foi proposta a experiência apresentada a seguir.

\section{MÉTODO}

Segundo Cross (1999) construir a pesquisa como um paradigma pode ser útil, em longo prazo, para práticas e ensino de design, pois o mistério da habilidade de design limita o "estudo da humanidade". Propõe-se aqui explorar o processo de integração e verificar a compreensão do mesmo por parte de acadêmicos de arquitetura e urbanismo, quanto submetidos a atividades de ateliê vertical, principalmente no que tange à interdisciplinaridade e à integração de conteúdos, assim como à inserção de inovações tecnológicas nesse processo.

Para este estudo realizou-se inicialmente uma pesquisa documental, baseada em revisão bibliográfica e em levantamento sistematizado das tratativas do tema nos congressos da Associação Brasileira de Ensino de Arquitetura (ABEA) e nos artigos disponíveis pelo Grupo de Pesquisa em Projeto de Arquitetura e Percepção do Ambiente (PROJETAR). Ainda documentalmente verificaram-se os regulamentos das maratonas de projeto - ateliê vertical do Curso de Arquitetura e Urbanismo da Unochapecó, entre 2013 e 2015, assim como seus resultados.

Numa etapa posterior realizou-se a aplicação de questionário, composto por uma maioria de questões fechadas, de múltipla escolha, com um campo para resposta aberta ao final, destinado a sugestões para a próxima edição. O questionário foi encaminhado a todos os 520 acadêmicos regularmente matriculados no curso, dos quais 101 responderam.

\section{MARATONA DE PROJETOS - ATELIÊ VERTICAL}

O Curso de Arquitetura e Urbanismo da UNOCHAPECÓ ofereceu, nos últimos três anos, uma atividade de integração tanto de conteúdos quanto de acadêmicos e docentes. Para tanto, a cada início de ano letivo, em 2013, 2014 e 2015, ocorreu a 'Maratona de Projetos - Ateliê Vertical', estimulando a integração de professores e acadêmicos de diferentes períodos do curso, fomentando a troca de experiências, visões de mundo e saberes diretamente ligados ao ofício de Arquiteto e Urbanista. A cada ano é definida pela comissão organizadora da atividade uma determinada temática de projeto e as propostas entregues são avaliadas por uma comissão avaliadora, sendo sempre definidos primeiro, segundo e terceiro lugares. 
A 'Maratona de Projetos - Ateliê Vertical' tem por objetivo lançar, em nível de Estudos Preliminares, soluções possíveis para contemplar uma temática em estudo. Através da produção dos acadêmicos, acredita-se não só criar um caminho para a discussão e ponderação de diferentes alternativas e soluções para a problemática em questão, mas sobretudo possibilitar a sensibilização e conscientização dos acadêmicos em relação a essa e/ou quaisquer outras intervenções arquitetônicas que venham a ser realizadas nas cidades. Considerando a arquitetura como elemento estruturador do território, acredita-se que a dinâmica do Ateliê Vertical funciona como campo de discussão para estratégias e desenhos que permitam extrapolar a escala e os limites das disciplinas tradicionalmente formatadas nas matrizes curriculares.

A participação discente acontece mediante a formação de equipes compostas por integrantes do primeiro ao último período do curso e os acadêmicos têm cinco dias úteis para desenvolvimento da proposta. Durante este período, os professores do curso são distribuídos nos ateliês e ficam à disposição das equipes para possíveis orientações, cada um contribuindo na sua área de conhecimento específico. Cabe ressaltar que o intuito da atividade é estimular a formação do profissional reflexivo e, portanto, a busca de orientação é voluntária e os docentes não participam ativamente no desenvolvimento das propostas. Trabalha-se com a autonomia do discente e seu protagonismo enquanto construção e articulação dos conhecimentos e conteúdos neste momento. Cada equipe elege um regente, geralmente de fases mais avançadas no curso, o qual fica responsável pela gestão do processo e integração de todos os membros do grupo.

A primeira edição, que ocorreu em 2013, teve como temática o centro de eventos da Unochapecó. No primeiro dia da atividade foram conferidas algumas aulas referentes à temática, com alguns estudos de caso e noções de dimensionamento; e as equipes foram formadas, pelos próprios acadêmicos, seguindo alguns critérios estabelecidos no regulamento da atividade. Do segundo ao quinto dia, as atividades foram desenvolvidas pelas equipes e a entrega era composta por quatro pranchas A2 e uma maquete física volumétrica. Nesta edição, a integração de saberes se deu por conta dos diferentes graus de conhecimento acadêmico, efetivando a troca dos mesmos nas discussões das tarefas. No primeiro instante já se percebeu que os veteranos repassavam aos mais novos as técnicas implantadas em aula, de discussões de conceitos, diretrizes projetuais e uma separação de tarefas após essa etapa, a partir do conhecimento dos componentes do grupo.

Os resultados desta edição foram mais conceituais e as maquetes foram volumétricas e finais, visto que o material que dispunham era basicamente papéis e EVA e iniciadas somente após as definições projetuais. Nas imagens a seguir é possível observar a integração dos grupos (Figura 2), orientação com docentes disponíveis nas salas (Figura 3) e resultados em maquetes (Figuras 3 e 4).

Figura 2 - Distribuição das atividades nos grupos.

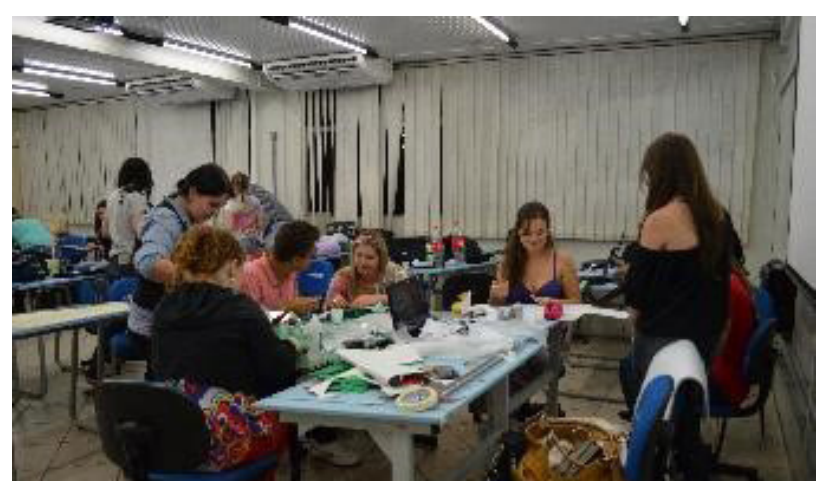

Fonte: Acervo das autoras, 2013.
Figura 3 - Orientação com docentes disponíveis em sala.

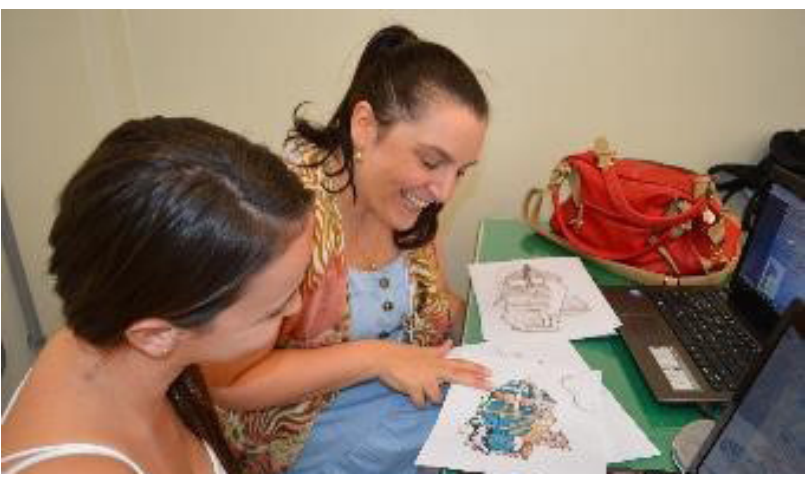

Fonte: Acervo das autoras, 2013. 
Figura 4 - Resultado projetual formal em maquetes.

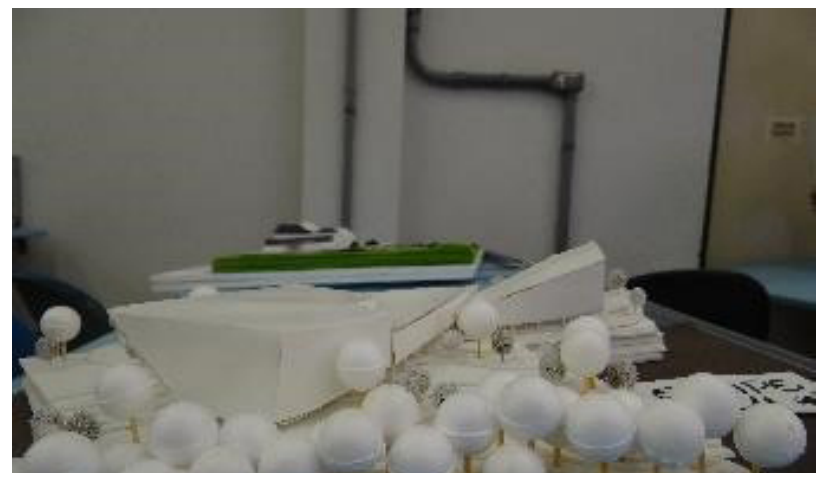

Fonte: Acervo das autoras, 2013.
Figura 5 - Resultado projetual formal em maquetes.

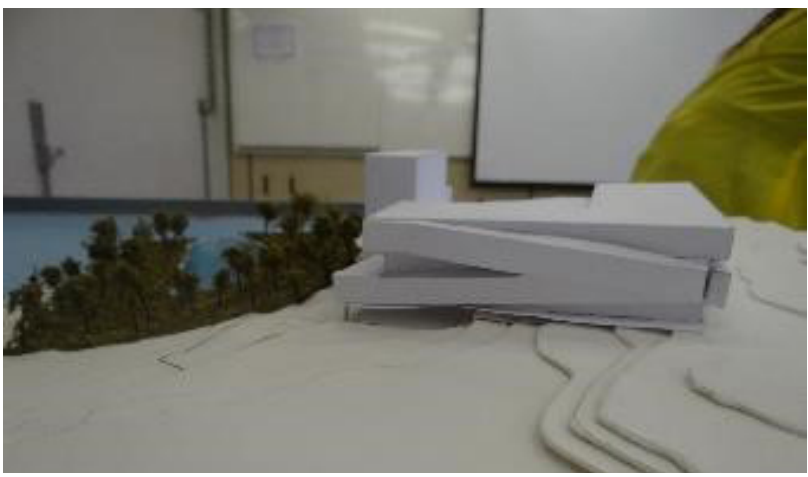

Fonte: Acervo das autoras, 2013.

Na segunda edição, em 2014, a temática referiu-se à requalificação da área central do município. Nesta edição, as equipes foram previamente divididas pela comissão organizadora da atividade, com o intuito de forçar mais a integração entre os acadêmicos. Outra alteração ocorrida na formatação à maratona refere-se à inserção da fabricação digital e da prototipagem rápida no processo de projeto, possibilitada pela inauguração do laboratório de prototipagem rápida na IES, o qual compõe a REDE PRONTO 3D (3) Laboratório de Prototipagem e Novas Tecnologias Orientadas ao 3D.

Segundo Batistello et. Al. (2015), a Prototipagem Rápida é um instrumento que auxilia e complementa as ações no processo de projeto, de modo a criar e produzir, em um curto espaço de tempo, protótipos reais e concretos de seus projetos, gerando alternativas na hora da apresentação dos mesmos. Isso diferencia a imagem bidimensional e facilita a compreensão e a percepção dos envolvidos no processo.

Nesta edição, como o laboratório Pronto 3D estava em fase de implantação, só havia disponível o uso da router CNC (4), com isso a integração de conteúdos aconteceu de forma vertical como no ano anterior, por meio de troca de conhecimentos, e com a inserção de novos conteúdos tecnológicos. Para não perder o foco da temática, a prototipagem rápida e fabricação digital foram inseridas como parte do resultado final, utilizada somente para detalhamento de um único objeto, um mobiliário urbano. Nesta maratona, a participação docente, principalmente dos conhecedores deste assunto, foi ampliada e a integração de saberes entre docentes e discentes mostrou-se mais efetiva que na versão anterior.

Os acadêmicos utilizaram a prototipagem rápida somente para a etapa final do projeto, deixando de lado a possibilidade de observar erros e acertos no processo projetual. No entanto, no mesmo momento em que montaram as peças dos mobiliários para a entrega final, perceberam as falhas principalmente estruturais de seus detalhamentos, e apesar de não haver tempo hábil para correção, reconheceram seus erros como a verificação disponível no próximo item deste artigo irá contemplar. As imagens 6, 7, 8 e 9 a seguir mostram imagens dos resultados e pode-se perceber que alguns mobiliários não seriam de execução viável.

Figura 6 - Corte na CNC.

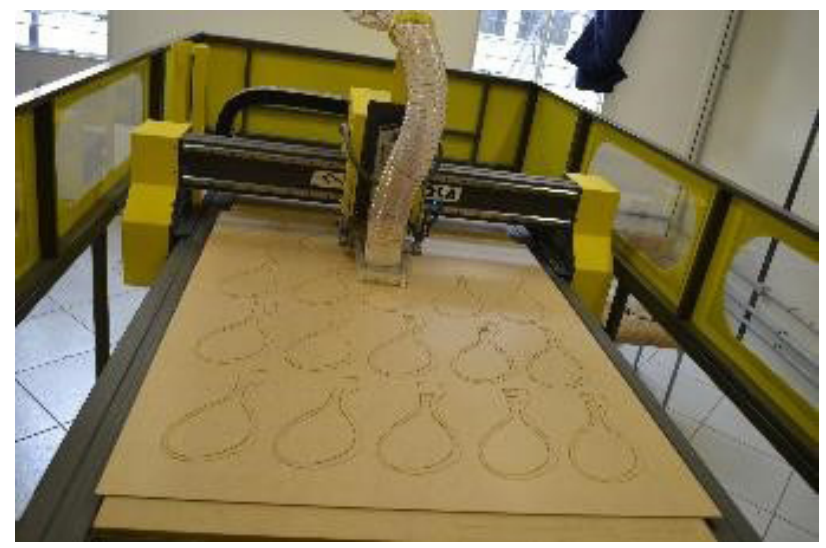

Fonte: Acervo das autoras, 2014.
Figura 7 - Maquete final.

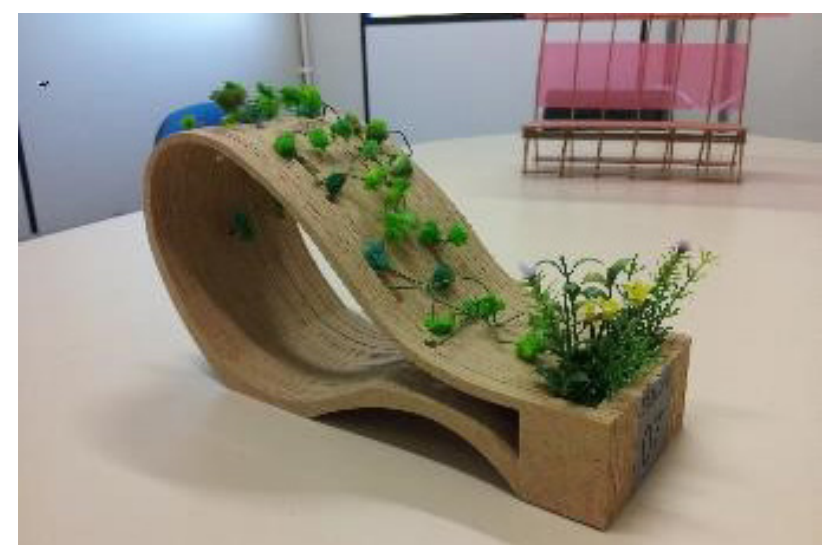

Fonte: Acervo das autoras, 2014. 
Figura 8 - Maquete final com problemas estruturais pequenos, possibilitando estudo de melhorias.

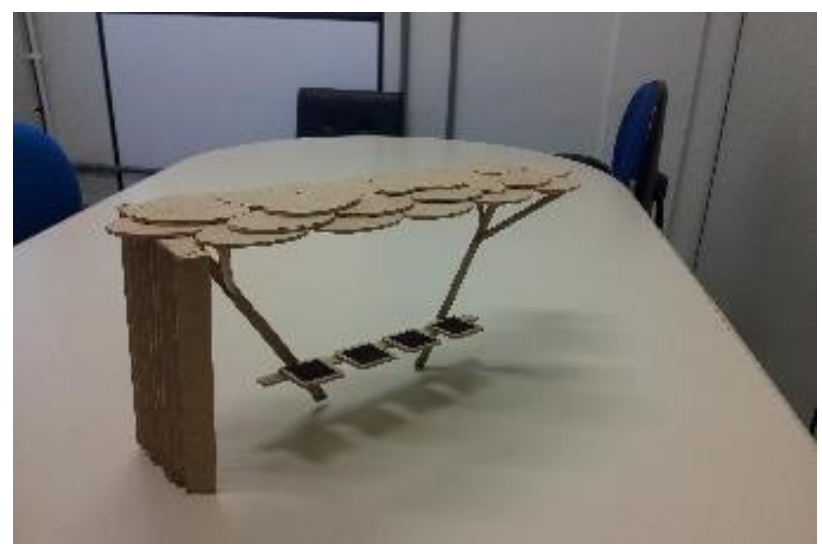

Fonte: Acervo das autoras, 2014
Figura 9 - Maquete final que demonstra a impossibilidade de execução projetual e seu devido uso proposto.

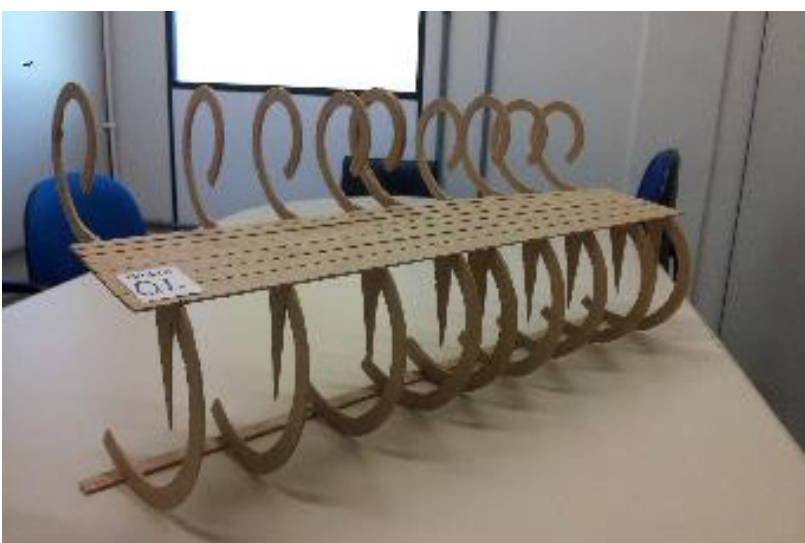

Fonte: Acervo das autoras, 2014

A terceira edição, ocorrida no início de 2015, abordou como temática os parklets. Do mesmo modo que na edição anterior, as equipes foram previamente divididas pela comissão organizadora, uma vez que o feedback de tal ação ocorrida no ano anterior, foi positivo tanto por parte dos discentes quanto docentes. Novamente, além das quatro pranchas contendo as informações da proposta, foram solicitados protótipos em escala reduzida, executados a partir das tecnologias digitais e do uso do PRONTO 3D.

Assim como na maratona anterior, os protótipos só foram produzidos ao final do processo projetual, e isso possibilitou aos acadêmicos refletirem sobre suas decisões, integrando conhecimentos principalmente estruturais, arquitetônicos e urbanísticos. Também foi possível averiguarem que caso tivessem se motivado a utilizar os protótipos durante o processo projetual, as melhorias a serem feitas seriam percebidas antecipadamente à entrega do resultado final e aproveitando que o tempo dado para o processo foi de cinco semanas, o que possibilitaria tentativas de erros e acertos a partir do protótipo.

A equipe vencedora, no entanto, montaria o parklet em uma avenida do município, com o intuito de questionar os habitantes sobre a utilização da cidade, e executar um projeto compreendendo a necessidade e importância do processo de integração de saberes na profissão de arquiteto e urbanista. Na Figura 10 a seguir, é possível perceber o corte do protótipo em maior escala, na cortadora a laser a Figura 11 mostra como ele foi entregue como objeto final da maratona.

Figura 10 - Corte feito na cortadora a laser.

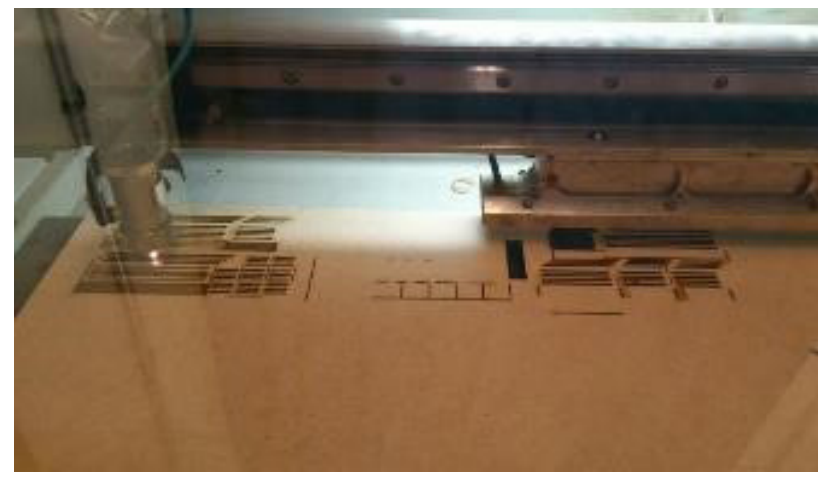

Fonte: Acervo das autoras, 2015.
Figura 11 - Maquete final do parklet da equipe vencedora.

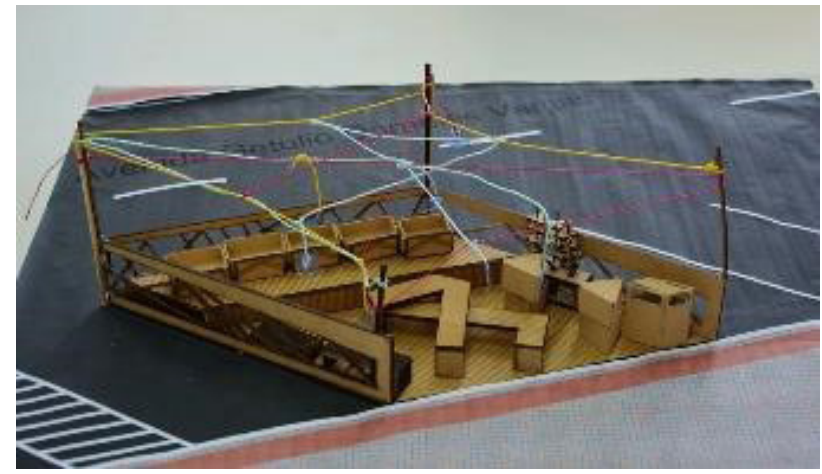

Fonte: Acervo das autoras, 2015.

O protótipo foi então fabricado na 1:1 e montado dentro da universidade (Figura 12) com o apoio da equipe de marcenaria da mesma, para que ainda houvesse chances de ajustes e correções antes da sua montagem final (Figura 13). 
Figura 12 - Montagem do Parklet em sala da Universidade para averiguação de erros finais.

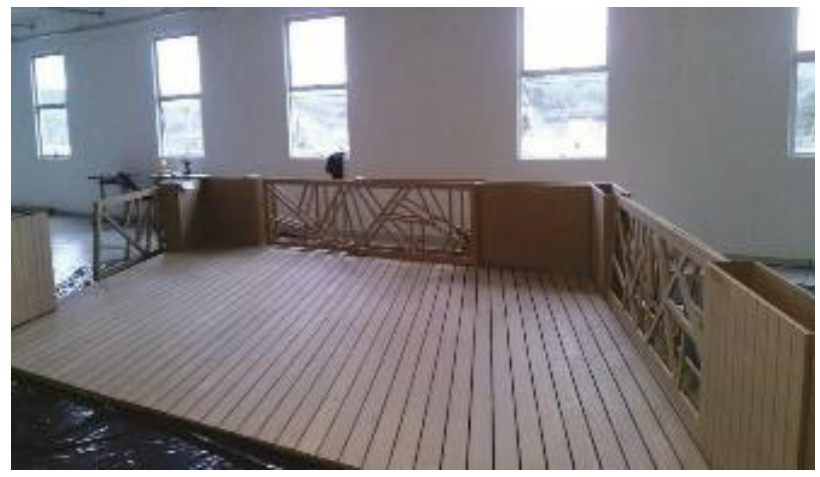

Fonte: Acervo das autoras, 2015.
Figura 13 - Montagem do parklet em avenida no centro da cidade.

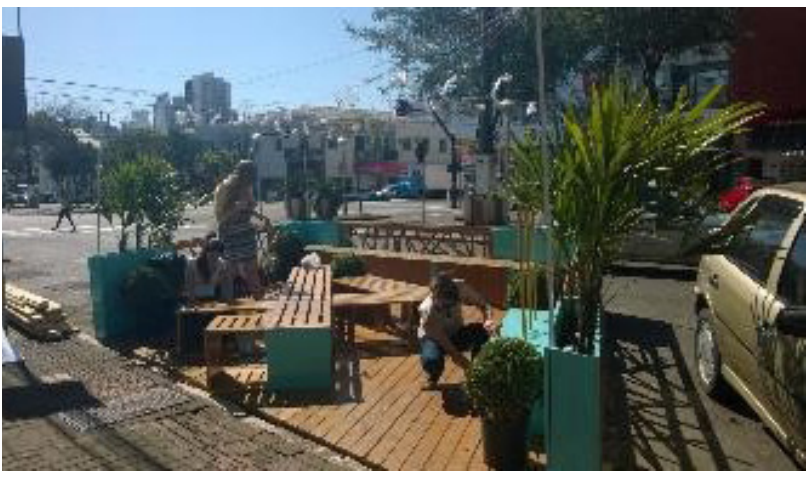

Fonte: Acervo das autoras, 2015.

Com a utilização da fabricação digital, ainda foi possível desmontar e remontar o parklet em mais um espaço, após a retirada do mesmo no tempo disponibilizado pela Prefeitura Municipal. Com isso ele foi montado com um espaço de permanência externa na Universidade com observa-se na Figura 14.

Figura 14 - Montagem do parklet na Universidade.

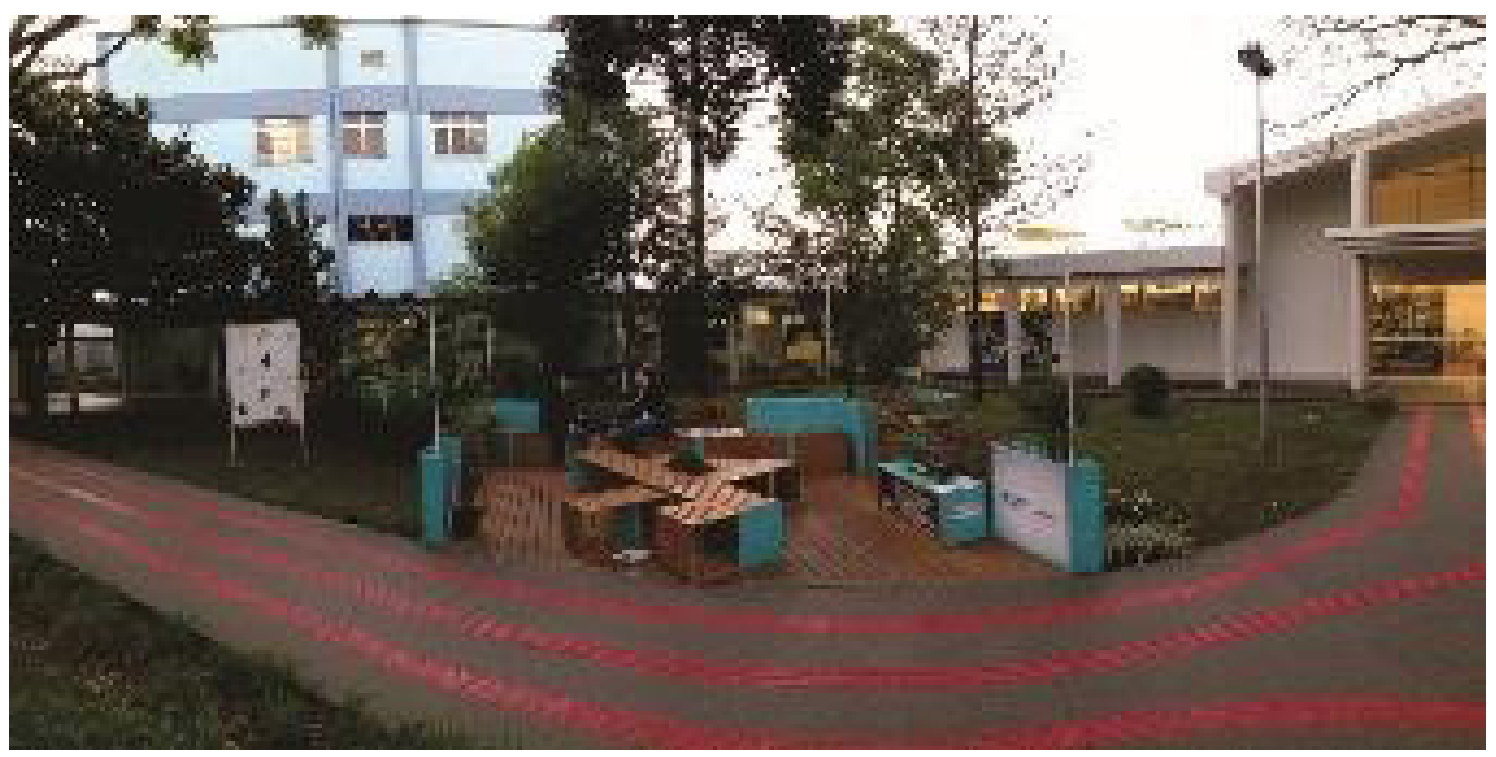

Fonte: Acervo das autoras, 2015.

\section{VERIFICANDO A INTEGRAÇÃO DE SABERES}

Tendo por base o objetivo de integração de saberes intrínseco à Maratona de Projetos, foram encaminhados questionários aos 520 acadêmicos regularmente matriculados no curso, a fim de se averiguar a eficácia da atividade com base na troca de conhecimentos acadêmicos entre os discentes participantes. O equivalente a 16\% dos acadêmicos matriculados respondeu aos questionários.

Com base nos dados coletados, primeiramente verificou-se o número de acadêmicos que participou das maratonas e em qual edição, para averiguar o percentual de acadêmicos participantes da pesquisa teve contato com a Prototipagem Rápida (PR) e Fabricação Digital (FD) no processo, pois a inserção desta tecnologia também modifica o processo de projeto e integra ainda mais conhecimentos. Percebeu-se, portanto que maioria participou de maratonas que já ofereciam trabalhos com PR e FD, uma vez que poucos participaram apenas da primeira edição, conforme pode-se observar na Tabela 1. 
Tabela 1 - Alunos respondentes que participaram da Maratona de Projetos em suas diversas edições.

Tabela 1 - Alunos respondentes que participaram da Maratona de Projetos em suas diversas edições.

\begin{tabular}{|c|c|c|}
\hline Edição & Quantidade de participantes & Percentual \\
\hline Apenas 1a & 09 & 8,91 \\
\hline Apenas $2^{a}$ & 05 & 4,95 \\
\hline Apenas 3aㅡ & 14 & 13,86 \\
\hline $1^{\mathfrak{a}}$ e $2^{\underline{a}}$ & 08 & 7,92 \\
\hline $1 \underline{a}$ e $3^{\underline{a}}$ & 05 & 4,95 \\
\hline $2^{a}$ e $3 \underline{a}$ & 19 & 18,81 \\
\hline Todas as edições & 40 & 39,61 \\
\hline Nenhuma edição & 01 & 0,99 \\
\hline
\end{tabular}

Fonte: Pesquisa realizada, 2016.

Os acadêmicos foram questionados sobre a integração de conteúdos e a integração entre os colegas durante a Maratona de Projetos e os resultados foram positivos em ambos os questionamentos, sendo que 92\% perceberam integração de conteúdos e 87\% perceberam integração entre acadêmicos, confirmando, em um primeiro momento, o atendimento ao objetivo principal da atividade.

Tendo por base as cinco áreas existentes no PPC do curso (Arquitetura; Urbanismo; História, Teoria e Crítica; Construtibilidade; e Conforto Ambiental) foram dadas sete opções de conteúdos aos acadêmicos e solicitou-se que marcassem as alternativas que acreditavam fazer parte da integração de conteúdos. Suas respostas indicaram as mais diversas combinações (Figura 2), também se evidenciando que alguns ainda não entendem o que é integração de conteúdos pois, embora na questão anterior tenham afirmado que ela existiu e nessa nova resposta optaram por somente uma área de conhecimento (12 acadêmicos, ou seja, 11,88\% do total). Inversamente, 2 dos que responderam não haver integração de conteúdos, na escolha das disciplinas indicaram que ela acontece. Ao todo, foi mais comum aos participantes verificar integração entre Projeto Arquitetônico, Planejamento Urbano e Conforto Ambiental, embora todas as outras áreas de conhecimento tenham sido citadas (Figura 15).

Figura 15 - Percepção da integração de conteúdos por parte dos acadêmicos participantes das maratonas de projeto.

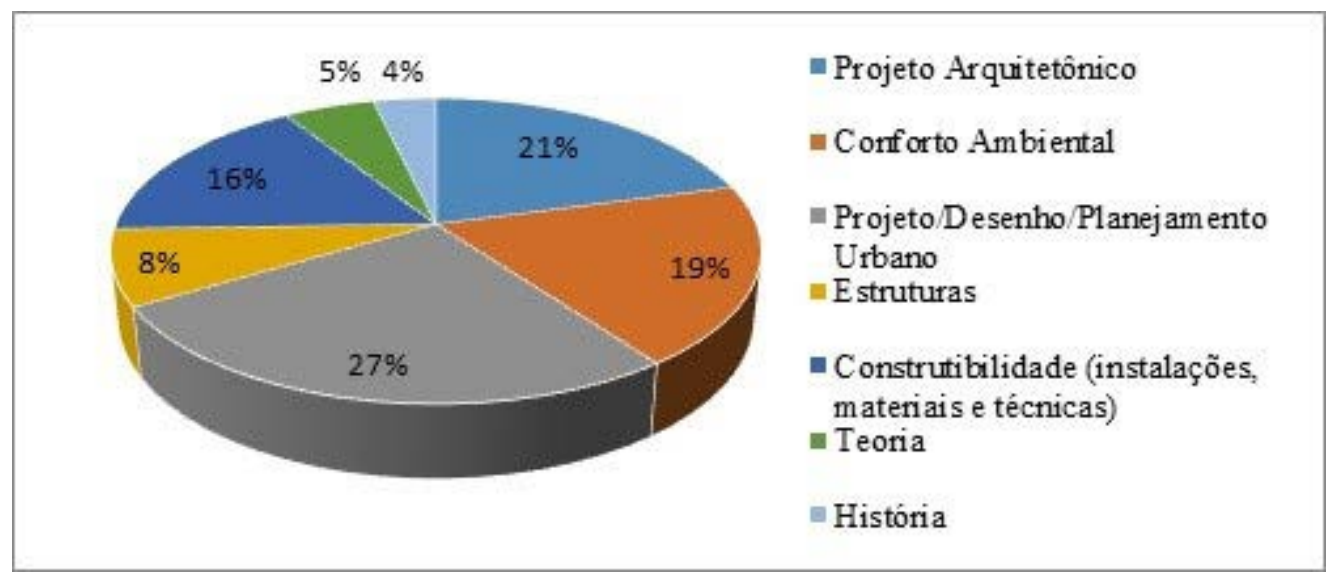

Fonte: Pesquisa realizada, 2016.

Com esse resultado foi possível verificar também quantos conteúdos os acadêmicos entrevistados conseguiram integrar durante a maratona de projetos, conforme se visualiza na Figura 16. A integração varia de duas a sete áreas. Foram desconsiderados aqui os acadêmicos que responderam que havia a integração, porém somente em uma disciplina, como explanado anteriormente. 
Figura 16 - Quantitativo de áreas integradas durante a projetação do objeto temático da maratona de projetos, de acordo com a percepção dos participantes da enquete.

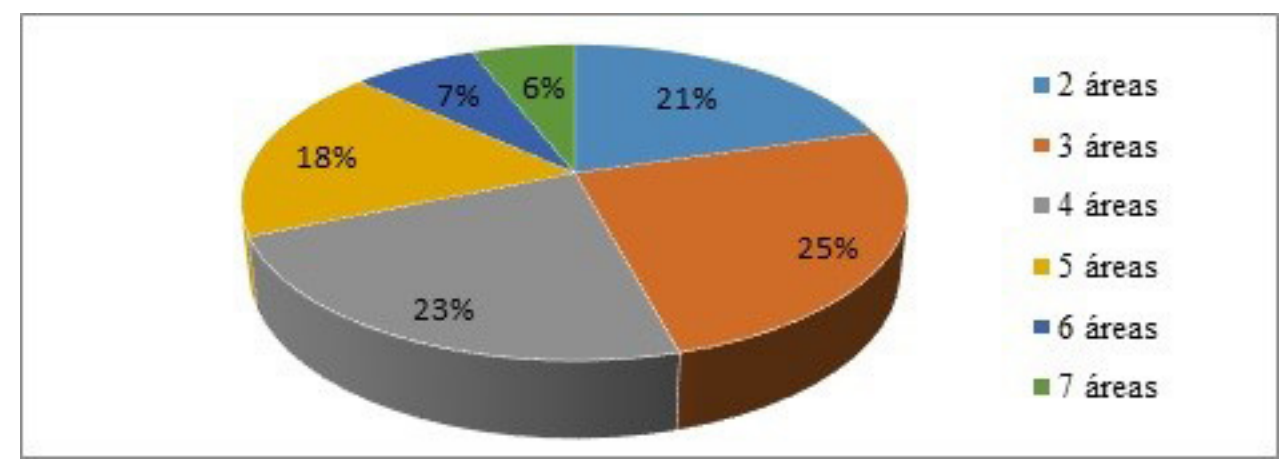

Fonte: Pesquisa realizada, 2016.

Questionamentos específicos em relação à inserção da PR e FD foram feitos no decorrer da entrevista, objetivando verificar o grau de entendimento e compreensão por parte dos acadêmicos quanto a possíveis melhorias no processo de projeto com a utilização desta nova tecnologia. Reforça-se aqui, que até o acontecimento da $3^{a}$ edição da Maratona de Projetos, nenhuma turma tinha cursado a componente curricular Fabricação Digital e Prototipagem Rápida, presente somente na nova matriz que iniciou em 2014. A partir da Figura 17 se observa que a grande maioria dos acadêmicos que participou das $2^{a}$ e $3^{a}$ edições da maratona concordam que a PR e FD agregam conhecimento além do adquirido na sala de aula.

Figura 17 - Conhecimento agregado por PR e FD durante a Maratona de Projetos.

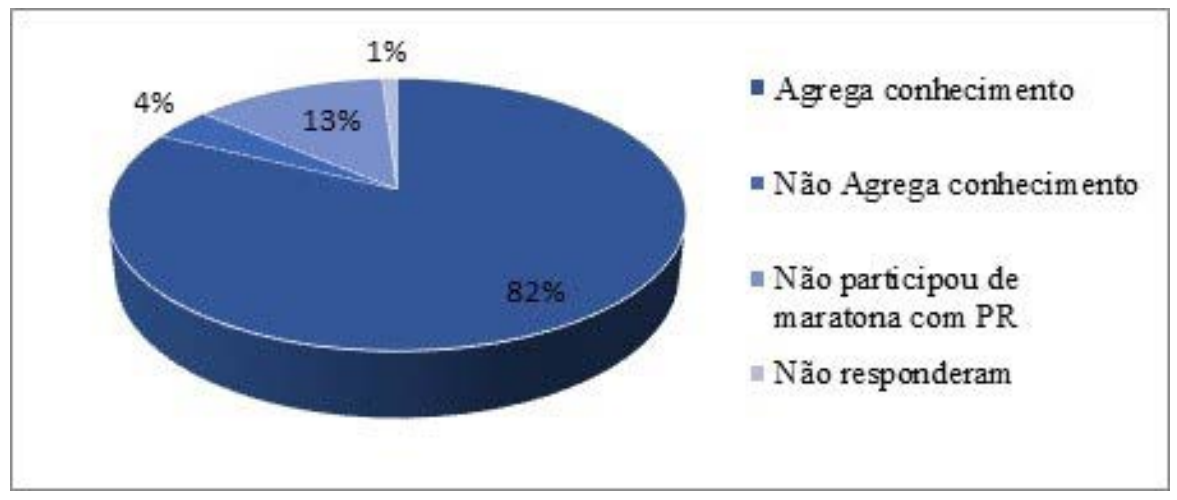

Fonte: Pesquisa realizada, 2016.

Quanto à inserção da prototipagem rápida no processo de projeto, ou quanto à validação do protótipo executado para verificar a melhoria do projeto final, as respostas também foram em sua maioria positivas. Quando questionados sobre a verificação de erros e acertos após a finalização do protótipo, a maioria respondeu que conseguiu observar (Figura 18) e quando a pergunta se referiu a oportunidade de melhorar o projeto após a verificação dos erros e acertos no protótipo o percentual ainda aumentou, ou seja, mesmo aqueles que não conseguiram verificar seus erros e acertos no protótipo se proporiam a melhorar e modificar seus projetos a partir desta verificação (Figura 19).

Figura 18 - Respostas dos acadêmicos quando questionados se o protótipo materializado proporcionou verificação de erros e acertos
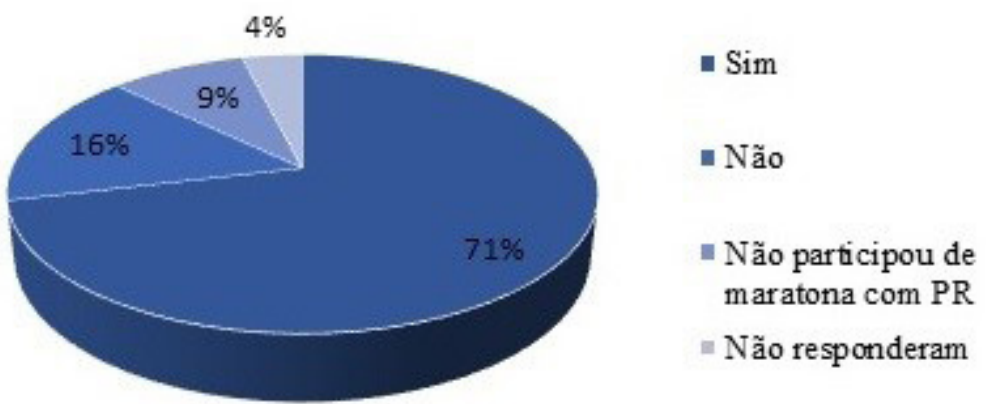

Fonte: Pesquisa realizada, 2016. 
Figura 19 - Respostas dos acadêmicos quando questionados a possibilidade de modificações no projeto após a verificação de erros e acertos no protótipo.

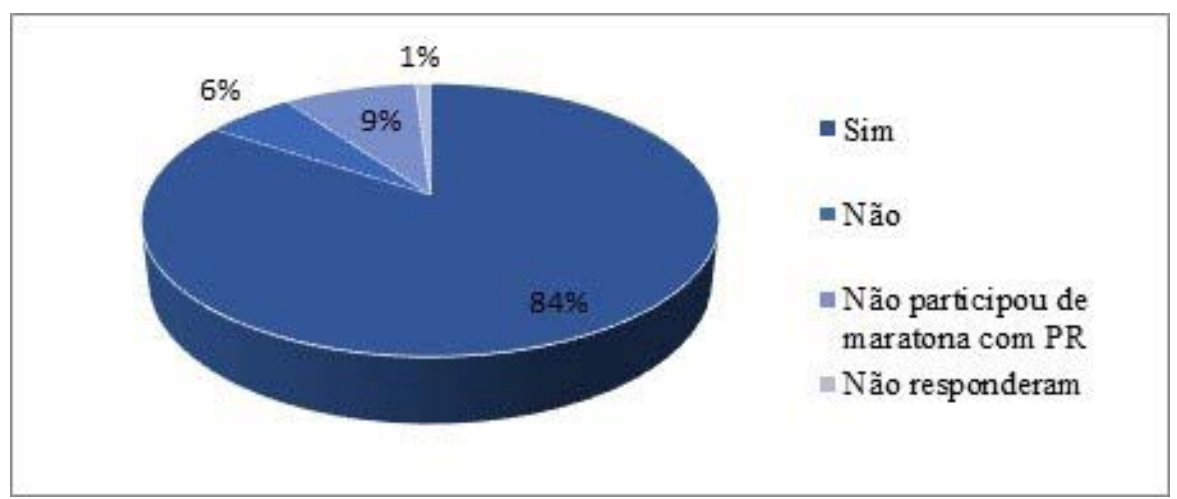

Fonte: Pesquisa realizada, 2016.

Contudo, mesmo com as respostas positivas descritas aqui, percebe-se na Figura 20 que, quando questionados sobre em que momentos o protótipo deve ser executado, boa parte dos participantes considera que a maquete deve fazer parte do processo projetual (42\%), uma pequena parcela enxerga que deve fazer parte somente do produto final (12\%), mas a maioria indica ambos (46\%), mostrando que sente a necessidade de verificar o protótipo como resultado do projeto e não somente como processo do mesmo para sua evolução e melhorias, fase na qual realmente ele é útil para a verificação de integração de conteúdos nos projetos em geral.

Figura 20 - Resposta dos acadêmicos referente à fase em que o protótipo deve ser executado.

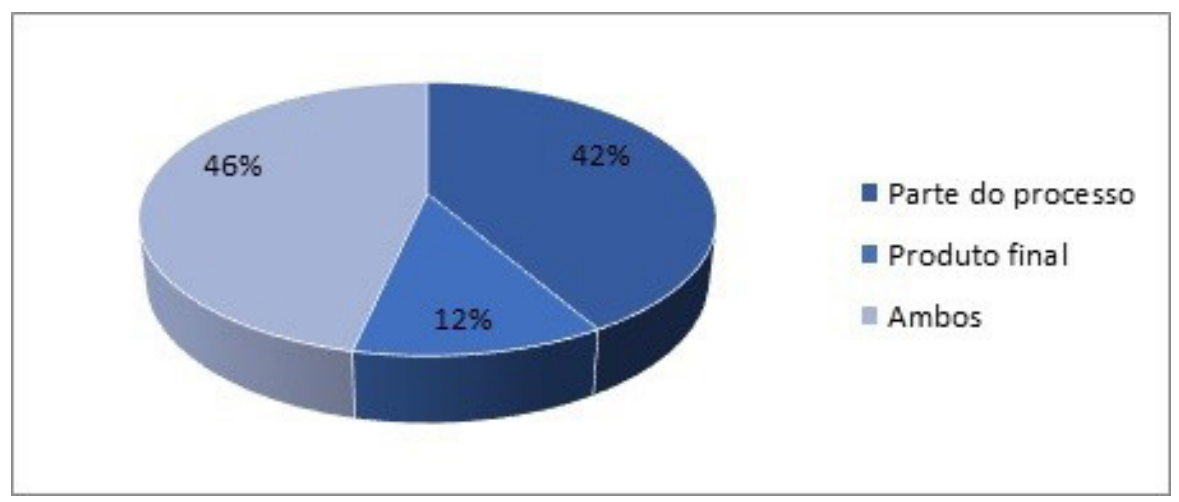

Fonte: Pesquisa realizada, 2016.

\section{CONSIDERAÇÕES FINAIS}

A crescente discussão da interdisciplinaridade nos cursos de Arquitetura e Urbanismo no Brasil demonstra a necessidade de mudança nos métodos de ensino tradicionais, baseados muitas vezes no isolamento de componentes curriculares, cada um com seus conteúdos específicos. Como afirmam Heck e Colusso (2009), esta ampliação da compreensão dos fenômenos permitida pela interdisciplinaridade tem se aproximado e invadido as bases do conhecimento em AU, e exige métodos de articulação e integração de temas e problemas.

Diversas são as experimentações e discussões de integração nas matrizes curriculares dos cursos de AU brasileiros, assim como são diversos os obstáculos encontrados em sua efetivação, tanto para discentes quanto para docentes. Por outro lado, Teixeira (2011) destaca que a atividade de projeto por si só já é integradora - ou pelo menos deveria ser - uma vez que a concepção das edificações envolve, em todo o processo de projeto, um conjunto de relações, as quais exigem a compreensão de diferentes conhecimentos, diferentes conteúdos. Sob esse ponto de vista, acredita-se que é o domínio dessas relações que precisa ser estimulado na formação profissional em questão, com vistas à autonomia discente, mas sempre com um suporte curricular, o qual pode se apresentar de diferentes formas e profundidades ao longo do curso e da evolução do acadêmico. 
Schön (2000) comenta que aprender todas as formas de talento depende de condições semelhantes às criadas em ateliês, nas quais há liberdade para aprender através do fazer, sem riscos e com acesso às orientações docentes, que seriam responsáveis por guiar o estudante a que veja por si próprio o que precisa ser visto. Entretanto, nas disciplinas de projeto tradicionais ministradas nos cursos de Arquitetura e Urbanismo esse ambiente de livre autonomia nem sempre acontece, uma vez que nem mesmo o professor responsável pelo componente curricular domina profundamente todos os conteúdos que podem estar relacionados à temática. No caso do Curso de Arquitetura e Urbanismo da Unochapecó, talvez isso só seja efetivamente possível na Maratona de Projetos, quando diversos professores ficam à disposição dos estudantes, os quais, neste momento, são os únicos responsáveis pelo sucesso do processo de projeto.

Teixeira (2011) afirma que a construção do pensamento crítico, capaz de orientar escolher e soluções, assim como de adquirir conhecimentos, domínios e metodologias que permitam opções contextualizadas, estão presentes na formação do arquiteto. Entretanto, não devem ser, cada um destes conhecimentos ou conteúdos, vistos de forma isolada, como objetivos em si mesmos. Mais importante que os interesses de cada área de domínio, deve ser a integração entre os conteúdos. O conhecimento fragmentado entre disciplinas impossibilita o vínculo entre as partes e o todo e deve ser substituído por um modo capaz de levar à compreensão das partes em seu contexto em sua complexidade, conforme afirma Morin (2006). Em resposta a isso, ressalta-se que a integração - que é pedagógica - não prejudica necessariamente o encaminhamento e a ordem construída dentro de cada disciplina, mas leva em conta a pertinência das conexões entre temas, conceitos e partes específicas de cada disciplina (SACRISTÁN, 1998, apud TEIXEIRA, 2011).

Os resultados aqui apresentados permitem concluir que a atividade proposta pela 'Maratona de Projetos - Ateliê Vertical' do curso de Arquitetura e Urbanismo da Unochapecó possibilita o processo de projeto com autonomia e protagonismo do acadêmico, o qual se percebe articulador de conteúdos e conhecimentos, com domínio das relações diversas que tangem a busca por soluções dos problemas expostos nas temáticas propostas.

A inserção de novas tecnologias ainda causa situações de compreensão aquém do esperado, se considerarmos as possibilidades de contribuição das mesmas no processo projetual como um todo, como foi possível observar na descrição dos acontecimentos do item 4, onde os acadêmicos mostram a falta de aproveitamento das tecnologias disponíveis no processo projetual. Acredita-se que ainda por falta do conhecimento necessário e da inserção das mesmas nos processos de projeto estimulados nas componentes curriculares projetivas. O acadêmico demonstra maior compreensão das relações entre os conteúdos que ele corriqueiramente discute de modo integrado no ambiente diário de ateliê, como a conexão entre os conteúdos de Projeto Arquitetônico, Conforto Ambiental e Projeto, Desenho e Planejamento Urbano.

Este estudo também permite identificar outras fragilidades na integração dos saberes, uma vez que os conteúdos de Teoria da Arquitetura e do Urbanismo não aparecem de modo significativo na abordagem dos estudantes, embora sejam necessários para o sucesso do processo de projeto.

Portanto, como percebe-se a partir do referencial adotado, no campo de AU a integração é um desafio relativamente recente, com discussão crescente e, mesmo que em momentos de experimentação, tem apresentado resultados bastante ricos na formação acadêmica. Os obstáculos a serem enfrentados ainda são variados, mas uma estruturação curricular clara e baseada na formação do profissional crítico e reflexivo se apresenta como um caminho promissor para que tanto discentes quanto docentes alcancem maior compreensão do projeto como um processo integrado.

\section{REFERÊNCIAS}

BATISTELLO, Paula; BALZAN, Katiane Laura; PIAIA, Luana Peroza; MIOTTO, Juliano. Prototipagem rápida e fabricação digital em ateliê vertical: do processo à materialização. In: CYBIS PEREIRA, A. T.; PUPO, R T. (Org.). Sigradi 2015: Project Information for Interaction. Palhoça: Rocha, 2015, p. 137-142.

CAVALCANTE, E.; VELOSO, M. (2013). Considerações sobre a integração de conteúdos disciplinares e o processo de projeto no trabalho final de graduação. In: SEMINÁRIO NACIONAL SOBRE ENSINO E PESQUISA EM PROJETO DE ARQUITETURA (PROJETAR 6). Anais... Salvador: PPGAU/FAU-UFBA, 2013, s/p. 
CROSS, N. Design Research: A Disciplined Conversation. Design Issues, 15(2), 5-10. The MIT Press: Massachussetts, 1999. http://doi. org/10.2307/1511837

ESPINDOLA, M. C. S.; SCHWERZ, A. (2013). Análise da integração entre disciplinas no curso de arquitetura e urbanismo da FURB. In: SEMINÁRIO NACIONAL SOBRE ENSINO E PESQUISA EM PROJETO DE ARQUITETURA (PROJETAR 6). Anais... Salvador: PPGAU/FAU-UFBA, 2013, s/p.

HECK, A.; COLUSSO, I. Novas Práticas Pedagógicas no Curso de Arquitetura e Urbanismo da UNISINOS: o Atelier de Projeto. Caderno ABEA, São Paulo, v. 33, p. 123-135, 2009.

JÁCOME, M. de F. T.; VIEIRA, N. M. (2013). A interdisciplinaridade no ensino de projeto: a proposta pedagógica do projeto integrado no curso de arquitetura e urbanismo da UNP-MosSoró. In: SEMINÁRIO NACIONAL SOBRE ENSINO E PESQUISA EM PROJETO DE ARQUITETURA (PROJETAR, 6). Anais... Salvador: PPGAU/FAU-UFBA, 2013, s/p.

LAWSON, B. Como arquitetos e designers pensam. São Paulo: Oficina de Textos, 2011.

MORIN, E. Introdução ao pensamento complexo. Porto Alegre: Sulina, 2006. 120 p.

SCHÖN, D. A. Educando o profissional reflexivo: um novo design para o ensino e a aprendizagem. Porto Alegre: Artes Médicas Sul, 2000.

TEIXEIRA, K. A. Projeto: o lugar pedagógico de vínculos. In: SEMINÁRIO NACIONAL SOBRE ENSINO E PESQUISA EM PROJETO DE ARQUITETURA (PROJETAR, 5). Anais... Belo Horizonte: Universidade Federal de Minas Gerais, 2011, s/p.

VIDIGAL, E. J. Um Estudo sobre o Ensino de Projeto em Curitiba. São Paulo, 2004. Dissertação (Mestrado em Arquitetura e Urbanismo), Faculdade de Arquitetura e Urbanismo, Universidade de São Paulo, 2004.

WEIZENMANN, J. M. DA S.; PACHALSKI, G. A.; DIEMER, M. J. Metodologia ativa e interdisciplinaridade: práticas pedagógicas no ensino de projeto de arquitetura na UNIVATES para a aprendizagem de competências. Caderno ABEA, São Paulo, v. 39, 2014, p. 533-548.

\section{NOTAS}

(1) Disponíveis em http://www.abea.org.br/?page_id=156, acessado em Maio de 2015.

(2) Disponível em http://projedata.grupoprojetar.ufrn.br/, acessado em Maio de 2015.

(3) A REDE PRONTO3D tem como objetivo a estruturação de centros estrategicamente localizados no estado de Santa Catarina, atualmente nas cidades de Lages, Criciúma e Chapecó; atende cursos de Design, Arquitetura, Engenharias, bem como todas as áreas que envolvam criação, auxiliando as diferentes etapas do processo de projeto. Disponível em: <http://www.redepronto3d.com/>. Acesso em: junho 2016.

(4) CNC - Computer Numeric Control - este equipamento trabalha com controle numérico computadorizado, auxiliado pelos sistemas CAD/CAM, para corte de peças e posterior montagem dos objetos. O disponível no Pronto 3D da Unochapecó é um equipamento que trabalha somente com os eixos $x$ e y, portanto as peças deveriam ser cortadas em planos 2D, para posteriormente, ao serem montadas, comporem os objetos em 3 dimensões.

NOTA DO EDITOR (*) O conteúdo do artigo e as imagens nele publicadas são de responsabilidade do(s) autor(es). 